\title{
Um sem-terra ideal para um movimento nacional: representações políticas do MST nas páginas do Jornal dos Trabalhadores Rurais Sem Terra ${ }^{1}$
}

Fernando Perli*

Resumo: Este artigo analisa as representações de sem-terra contidas nas páginas do Jornal dos Trabalhadores Rurais Sem-Terra num período de formação da Nova República e de articulação nacional do Movimento dos Trabalhadores Rurais Sem-Terra (MST). O tabloide, organizado por entidades de apoio e direção do MST, tornou-se instrumento de difusão de propostas e perspectivas da mobilização, idealizando o trabalhador rural sem-terra como protagonista da luta pela reforma agrária. Tais representações foram tecidas por intelectuais, jornalistas, militantes de entidades de apoio e lideranças sem-terra que, nas tensões de elaboração e apropriação do informativo, delimitaram um espaço de atuação política em que, atrás dos aparentes propósitos da reforma agrária, encontrava-se a luta pela comunicação.

Palavras-chave: Jornal. Representações. Movimento dos trabalhadores rurais sem-terra.

\section{Introdução}

O Movimento dos Trabalhadores Rurais Sem-Terra (MST) tornou-se no recente cenário político brasileiro objeto de intensos debates e estudos. Em sua pauta, desde as origens da orga-

* Professor Adjunto I da Universidade Federal da Grande Dourados (UFGD). E-mail: FernandoPerçi@ufgd.edu.br. 
Um sem-terra ideal para um movimento nacional: representações políticas...

nização até a internacionalização das causas campesinas, muitos significados foram dados aos trabalhadores rurais sem-terra. Neste contexto de mobilizações, ocuparam condição estratégica os meios de comunicação do MST, organizados por lideranças sem-terra, intelectuais, jornalistas, ativistas, estudantes e religiosos que compuseram entidades de apoio à causa do movimento social.

Entendidos como espaços de tensões e de lutas simbólicas, os instrumentos de difusão de representações políticas foram ampliados e configurou uma identidade sem-terra, colocando na pauta da Direção Nacional do MST a elaboração de uma política de comunicação que constituiu um vasto e importante corpo documental para a compreensão da história do movimento social. Compõe este conjunto de materiais produzidos ou apropriados pelo MST o Boletim e Jornal dos Trabalhadores Rurais Sem Terra, os Cadernos de Formação, os Boletins e Cadernos de Educação, os Cadernos de Cooperação Agrícola, as coleções Faz̧endo História e Faz̧endo Escola, a página virtual www.mst.org.br, o CD Arte em Movimento, o Projeto Terra, a Revista Sem-Terra e uma quantia significativa de audiovisuais. ${ }^{2}$

Dentre esta variedade de meios de comunicação destinados à organização dos sem-terra, podemos mencionar o mais antigo instrumento de apoio à luta: o Jornal dos Trabalhadores Rurais Sem-Terra (JST). Para ter-se ideia da função ocupada pelo informativo no quadro de formação do movimento, no final da década de 1990 , há quase vinte anos de circulação, a trabalhadora rural sem-terra Judith Strozake referiu-se ao tabloide como "patrimônio político do MST e da classe trabalhadora" por resistir ao tempo e "às imposições da comunicação burguesa”. (JORNAL SEM TERRA, 1999, n. 189).

Expressões como "patrimônio" e "comunicação burguesa" sugerem um amplo campo de análise das representações políticas do MST. Consideramos representações, nos termos do historiador inglês Eric Hobsbawn, "construções mentais". (BLACKBURN, 1992, p. 25). Estas constituem uma ideologia política e são difundidas por meios de comunicação que "expressam atos coletivos" (ANSART, 1978, p. 36), fundamentam a organização e unificam um conjunto de ideias como legítima manifestação de lideranças do movimento social. Representar consiste numa interpretação de algo que está ausente ou na idealização de uma proposta para identificação do grupo social. (CHARTIER, 1996, p. 47).

Anos 90, Porto Alegre, v. 20, n. 38, p. 327-352, dez. 2013 
As ideais contidas nos meios de comunicação do MST integram conjuntos articulados de representações, que se ampliaram na medida em que as demandas do movimento social se expandiram de um plano regional para a internacionalização da luta dos sem-terra. É possível auferir num amplo material produzido para a formação de quadros do MST uma variedade de representações, como as de passado, de socialismo, de trabalho, de escola, de intelectuais, de massas e de trabalhadores rurais sem-terra idealizados na consolidação do movimento em nível nacional.

O Jornal dos Trabalhadores Rurais Sem-Terra, mais conhecido nos círculos de leitura da militância como O Sem Terra, antes de se transformar em jornal, entre 1981 e 1984, foi organizado como Boletim Informativo da Campanha de Solidariedade aos Agricultores Sem Terra (BST) de Ronda Alta (RS), sob responsabilidade de entidades de apoio à reforma agrária, como a Comissão Pastoral da Terra (CPT), a Pastoral Universitária do Rio Grande do Sul (PU-RS), o Movimento de Justiça e Direitos Humanos do Rio Grande do Sul (MJDH-RS) e o Centro de Assessoria Multiprofissional (CAMP) de Porto Alegre (RS) que, num sentido geral, engajavam-se no movimento de redemocratização política do Brasil.

Em meio à diversidade de representações, interessa-nos as de um trabalhador sem-terra idealizado por lideranças do MST e produtores do jornal num contexto em que forças políticas em defesa da reforma agrária, em meados da década de 1980, depararam-se com a atuação de setores políticos compromissados com os interesses da União Democrática Ruralista (UDR) ${ }^{3}$ na elaboração do Plano Nacional de Reforma Agrária (PNRA) e na Assembleia Constituinte da Nova República.

Num primeiro momento, entre 1981 e 1984, trataremos da organização do Boletim Sem-Terra e das transformações que repercutiram na publicação do tabloide em 1984, ano de fundação do MST. Neste período, a participação da CPT na articulação de trabalhadores rurais sem-terra de várias regiões do Brasil marcou-se por um forte ideário cristão que, em meio às tensões políticas, mudaram a orientação do MST para uma campanha de sindicalização e partidarização de quadros do movimento à estrutura da Central Única dos Trabalhadores (CUT) e ao Partido dos Trabalhadores (PT). 
Um sem-terra ideal para um movimento nacional: representações políticas...

Diante da formação da Direção Nacional do MST, num segundo momento, entre 1984 e 1987, analisaremos a transformação do boletim em Jornal dos Trabalhadores Rurais Sem Terra, que se tornou porta-voz das aspirações políticas de lideranças sem-terra articuladas à militância de jornalistas engajados na produção do tabloide. Assim, o jornal tornou-se mecanismo de difusão das propostas políticas da Executiva Nacional do MST que, ao defender posições, projetou a atuação dos trabalhadores rurais sem-terra na luta pela reforma agrária. Lançadas pelo informativo em vários ambientes de mobilização, estas projeções demonstram as competências atribuídas pela direção do movimento aos trabalhadores rurais sem-terra, em grande parte, produto da idealização e campo de representações políticas da luta pela terra.

\section{De boletim a tabloide: o ideário cristão e a partidarização da luta pela terra}

No Estado do Rio Grande do Sul, na transição da década de 1970 para 1980, a contestação de entidades civis e organizações não governamentais (ONGs) ao regime militar trilharam os caminhos de assessoramento e mobilização dos trabalhadores rurais que organizaram acampamentos nos municípios de Ronda Alta (RS) e Sarandi (RS). Montado em 1981 e considerado um dos marcos das origens do MST, o acampamento da Encruqilhada Natalino possibilitou uma sistematização das experiências de luta através de anotações e definições de metas. (IOKOI, 1991, p. 49-70).

Com o objetivo de explicar os propósitos dos agricultores do acampamento perante a sociedade civil, bem como conquistar apoio de grupos políticos e sociais, amparados pela CPT, PU e MJDH, os trabalhadores rurais escreveram a Carta dos Colonos acampados em Ronda Alta. Entre explicações das quinhentas famílias e justificativas para lutar pela terra, evidenciou-se no documento a necessidade de conquistar apoios. Mais do que uma exigência específica dos trabalhadores rurais, a carta foi uma contestação às transformações modernizadoras que afligiam a atividade agrícola tradicional. A frase que a finalizou, "Terra para quem nela trabalha", 
além de questionar o uso da mesma para fins especulativos, reivindicava condições básicas de vida e produção.

Sob forte influência cristã, a carta sustentou a elaboração de um boletim, entendido como um material escrito mais amplo. Apesar da reprodução da carta e sua distribuição serem uma alternativa simples de comunicação, a montagem de um informativo requeria mais estruturação, tornando importante a ajuda de entidades na produção. Em comunhão com a CPT, universitários de Porto Alegre (RS) propuseram sistematizar ideias dos acampados e ganharam apoio do $\mathrm{MJDH}$, que cedeu espaço na sede localizada na capital gaúcha para confeccionarem o informativo. O MJDH era mantido por doações e tinha uma estrutura organizacional que não dispunha de funcionários ou associados, contando com o trabalho de pouco mais de uma dezena de funcionários. (WENDHAUSEN, 2003, p. 81).

Nascia uma proposta de meio de comunicação voltado para a solidariedade aos acampados da Encruzilhada Natalino. O público a que se destinou a edição número um do Sem Terra foi composto por lideranças sindicais, religiosos, parlamentares, entidades civis, federações de trabalhadores e integrantes da sociedade de Ronda Alta (RS). O objetivo do boletim foi alcançado na medida em que o acampamento passou a receber correspondências de entidades civis de várias regiões do Brasil que se sensibilizaram com os colonos.

O planejamento da periodicidade e da tiragem dependia dos acontecimentos da luta dos acampados, da coleta de informações e da militância na organização do informativo. Um agravante para a publicação era a Lei de Segurança Nacional (LSN), que dificultava a exposição dos colaboradores, da responsabilidade jornalística e de expediente, assumidos coletivamente pelas entidades solidárias à luta dos trabalhadores rurais.

Apesar destes entraves, o envolvimento destas entidades na elaboração do Boletim Sem Terra resultou, num período de dois meses, em nove edições. A função atribuída ao boletim era de instrumento para a troca de experiências e socialização política entre entidades civis, sindicatos, ONGs e partidos políticos que se agregavam num projeto de fortalecimento de diversas lutas pela terra surgidas no centro-sul do Brasil, criando uma rede de sociabilidade que culminou, em 1984, com a fundação do MST. Por meio do embate político na 
Um sem-terra ideal para um movimento nacional: representações políticas...

construção da notícia, cresceram a rede de solidariedade em torno dos acampados e a divulgação das lutas similares que surgiram no interior do Rio Grande do Sul, nos Estados de Santa Catarina, Paraná, Mato Grosso do Sul, São Paulo, Espírito Santo e Bahia. O papel assumido pelo boletim foi o de auxiliador na agregação de valores e de apoios institucionais através da promoção de contatos entre lideranças de acampamentos, de sindicatos, de igrejas e de entidades que se associavam à causa política dos colonos de Ronda Alta (RS).

$\mathrm{Na}$ identificação da CPT com os colonos da Encruzilhada $\mathrm{Na}$ talino, várias igrejas passaram a declarar apoio às famílias através do Conselho Nacional de Igrejas Cristãs (CONIC). Mantendo uma estreita relação com a Confederação Nacional dos Bispos no Brasil (CNBB), o CONIC visava fortalecer a solidariedade aos excluídos da terra através da mobilização de entidades religiosas. A relação dos agricultores com o Conselho integrou lideranças religiosas e a comissão de lavradores do acampamento para visitarem igrejas como forma de ampliar a solidariedade aos colonos. Assim, as formas de apoio dadas por entidades aos acampados tornaram-se externas, demandando a elaboração de novos espaços de divulgação da luta.

O envio de mensagens de simpatizantes e de direções de entidades sindicais, religiosas e políticas de várias regiões do Brasil em apoio à luta dos acampados de Ronda Alta (RS) contribuiu para a organização no Boletim Sem Terra da seção "Solidariedade". Sem definição de responsável pela sua composição, em meio a um projeto coletivo de publicação, na seção, foram transcritas as cartas vindas de variados pontos do Brasil, desde pequenas frases até detalhes do que haviam recebido de entidades ou trabalhadores rurais identificados com a luta. As cartas com mensagens curtas e enfoques mais diretos eram vistas pelos responsáveis do boletim como uma alternativa mais eficaz, importante para a manutenção de grupos que propunham ocupar outras terras.

Além do caráter pessoal e sentimental, as cartas era um elemento aglutinador dos trabalhadores rurais, pois também simbolizavam o tamanho do apoio e o crescimento da luta de agricultores sem-terra em outros Estados. A divulgação das cartas criou uma socialização política entre manifestações regionais pela reforma agrária na medida em que produziu uma identidade de luta. Esta

Anos 90, Porto Alegre, v. 20, n. 38, p. 327-352, dez. 2013 
constituiu-se sob um ideário cristão em que a influência da CPT na Campanha de Solidariedade aos acampados de Ronda Alta (RS) se somou à emergência de lideranças de acampados que defendiam um projeto de autonomia através da formação de um movimento social que arregimentasse lutas regionais pela terra eclodidas no centro-sul do Brasil. (BOLETIM SEM TERRA, 1983, n.19).

Para dar representatividade coletiva às inúmeras entidades que lançaram apoio aos trabalhadores rurais, formou-se o Comitê de Apoio aos Agricultores Sem Terra do Rio Grande do Sul, integrado por representantes da CPT e do CONIC, do MJDH e lideranças de agricultores do acampamento de Ronda Alta (RS).

Em março de 1982, o Comitê de Apoio assumiu a responsabilidade do Boletim Sem Terra, recebendo contribuições de entidades religiosas, dos direitos humanos e sindicais, para a manutenção do informativo. Até 1983, quando deixou de atuar como responsável, o Comitê promoveu um aumento quantitativo e qualitativo do boletim, alcançando a tiragem de 3000 exemplares e remodelando as abordagens, com uma linguagem mais crítica e de denúncia da violência no campo. No período foi publicado o primeiro boletim em fotocomposição e a circulação se estendeu para os Estados do Rio Grande do Sul, Santa Catarina, Paraná, São Paulo e Mato Grosso do Sul.

Nas discussões sobre articulação regional desenvolvidas nos Encontros de Trabalhadores Sem-Terra nas cidades de Medianeira (PR) e Goiânia (GO) em 1982, o Comitê de Apoio do Rio Grande do Sul foi citado como exemplo de organização e de ativa publicação do boletim. Por estar mais estruturado em relação a informativos de outros movimentos sociais rurais, o Sem Terra foi escolhido como órgão de divulgação da luta nos Estados do centro-sul. (BOLETIM SEM TERRA, 1982, n. 24).

Porém, críticas referentes à acessibilidade do boletim nas bases do movimento foram sentidas. Nas discussões sobre estratégias para atingir um leitor ideal para o movimento social, neste caso os trabalhadores rurais localizados em inúmeros pontos de mobilização, evidente era a ausência de definição do leitor do boletim que, em sua maioria, constituía-se como assinante coletivo, tais como instituições sociais e políticas que, por demandas próprias, agregavam-se à luta dos sem-terra.

Anos 90, Porto Alegre, v. 20, n. 38, p. 327-352, dez. 2013 
Um sem-terra ideal para um movimento nacional: representações políticas...

A reivindicação de lideranças para aproximar o boletim do cotidiano dos sem-terra em acampamentos que se multiplicavam integrou um contexto de debates sobre o papel das entidades de apoio na organização dos trabalhadores rurais. Procurou-se, mesmo que timidamente, apresentar no boletim os interesses daqueles que divulgavam ideias dos e para os sem-terra. A melhoria da produção do informativo foi verificada com a aproximação entre o Comitê de Apoio e as entidades sindicais que possuíam condições para a produção gráfica. Os contatos com ONGs que iniciavam trabalhos de educação popular e a abertura de espaço no boletim para publicidade eram estratégias bem vistas pelos integrantes do Comitê de Apoio.

$\mathrm{Na}$ carta Aos companheiros sem-terra do Brasil, escrita por lideranças de trabalhadores rurais no final do Encontro em Goiânia (GO) e publicada pelo Boletim Sem Terra, os rumos da organização de um movimento nacional eram traçados pela atuação dos sem-terra nos sindicatos e associações populares locais. (BOLETIM SEM TERRA, 1982, n. 28). O futuro da organização estaria relacionado com as conquistas de espaços políticos por trabalhadores rurais em entidades sindicais e partidárias. Para isso, a opção pela sindicalização e filiação partidária foi, em sua maioria, de oposição, por meio da atuação de lideranças sem-terra em Sindicatos de Trabalhadores Rurais (STRs) de maneira "combativa", conforme sugeria a Central Única dos Trabalhadores (CUT), ou pela filiação ao Partido dos Trabalhadores (PT).

A orientação decorreu de um distanciamento político entre lideranças sem-terra e a Federação dos Trabalhadores de Agricultura do Rio Grande do Sul (FETAG-RS). A estrutura de conquista e produção em áreas rurais no Rio Grande do Sul - e podemos estender a observação para outros Estados em que tais lutas se desenvolviam - criaram um vasto campo de novos interesses que os sindicatos rurais não estavam preparados para incorporar. (NAVARRO, 1996). Num clima em que germinaram as primeiras iniciativas de oposição sindical à FETAG (RS), o boletim criticou abertamente as posições da entidade com relação aos papéis exercidos por lideranças sem-terra dentro dos STRs.

Sendo denunciada por adotar estratégias políticas para evitar a conquista de espaço de lideranças sem-terra e agentes de apoio 
na direção dos movimentos regionais, a FETAG (RS) foi divulgada no boletim como uma entidade sindical contrária à autonomia dos trabalhadores rurais, aos apoios de diversas instituições para a afirmação dos sem-terra e por promover o afastamento de entidades que durante o período de organização em Ronda Alta (RS) estiveram ao lado dos colonos. (BOLETIM SEM TERRA, 1984, n. 34).

A FETAG enfrentava oposição sindical de jovens líderes que integravam a CUT, sendo noticiada como entidade pelega e moderada, inadequada para as ações estratégicas que cresciam com a organização dos movimentos rurais regionais. Participantes das atividades usuais da Igreja Católica e filhos de pequenos produtores que viviam o drama da crescente crise econômica, esses jovens sindicalistas formaram-se em cursos rápidos promovidos pela CUT, representada por STRs de várias regiões do Brasil. ${ }^{4}$ Em meio ao aumento dos protestos dos sem-terra, esses jovens tornaram-se militantes de um "novo sindicalismo" e exerceram papel de animadores de reuniões que estimularam a criação de oposições sindicais mediante o fortalecimento de núcleos locais de movimentos sociais e a participação ativa na política municipal. (COMERFORD, 2003).

Ao considerarmos que a organização interna do Boletim Sem Terra configurava-se como um "campo simbólico", para usar a expressão de Bourdieu (2001), cuja eficácia reside na possibilidade de ordenar o mundo social dos sem-terra através de discursos, mensagens e representações que simulam a estrutura real das relações sociais, pode-se perceber que a busca de participação de lideranças sem-terra em sindicatos e partidos políticos encontrou no meio de comunicação uma estratégia para divulgar suas ações como também um campo de tensões entre jornalistas, religiosos e as próprias lideranças de trabalhadores rurais.

Para Bourdieu:

“[..] os sistemas simbólicos distinguem-se fundamentalmente conforme sejam produzidos e, ao mesmo tempo, apropriados pelo conjunto do grupo, ou pelo contrário, produzidos por um corpo de especialistas e, mais precisamente, por um campo de produção e de circulação relativamente autônomo”. (BOURDIEU, 2000, p. 143). 
Um sem-terra ideal para um movimento nacional: representações políticas...

Tais tensões, muito características entre lideranças sem-terra e entidades de apoio, tornaram-se evidentes num espaço de luta pelo monopólio da autoridade daqueles que enunciavam o "ser sem-terra". Assim, em 1983, estudantes, religiosos e diversos profissionais com inserção orgânica em movimentos sociais, dentre os quais, militantes e jornalistas que contribuíram na elaboração do Boletim Sem Terra, fundaram o Centro de Assessoria Multiprofissional (CAMP), uma ONG para atuar na educação popular e na organização de movimentos populares.

Da organização embrionária do CAMP, marcada por reuniões desde 1981, participaram os funcionários públicos Rolf Hackbart, Ricardo Franzói e João Pedro Stédile; os sindicalistas Jairo Carneiro, Selvino Heck e Natalício Correa; o ex-integrante da Vanguarda Popular Revolucionária (VPR) Laerte Meliga e a estudante de pedagogia Conceição Paludo.

Como Centro de Educação Popular, o CAMP aplicou cursos rápidos de política e organização sindical para trabalhadores rurais. Sua sede abrigou o Comitê de Apoio e a produção do Boletim Sem Terra entre março de 1983 e fevereiro de 1985, dando assessoramento para a transformação do boletim em tabloide. (BOLETIM SEM TERRA, 1984, n. 35).

Um dos pontos importantes que refletiu a presença de integrantes do CAMP na organização do boletim foi o debate sobre a adoção de critérios para a obtenção de facilidade na leitura, exigindo mudança gráfica, com uma composição que pudesse chamar atenção dos leitores trabalhadores rurais. Além disso, em novembro de 1983, o Sem-Terra alcançou a tiragem de 5000 exemplares. Considerada histórica por produtores da notícia e lideranças sem-terra, a edição n ${ }^{\circ} 33$ deu cobertura à vitória dos lavradores de Ronda Alta (RS), abordou a história da Encruqilhada Natalino, lançou uma proposta de embate à Lei de Segurança Nacional (LSN) e publicou o Expediente, até então cerceado pela repressão, com os nomes de jornalistas responsáveis e colaboradores. A edição foi a primeira a descrever a responsabilidade jornalística de Flademir Araújo, então militante do Sindicato dos Jornalistas do Rio Grande do Sul, constando dados sobre o seu registro profissional. No setor de arte, Humberto Monteiro, Laerte Meliga, Celso Schroder e 
Antonio Rocha, assumiram suas participações. A distribuição ficou sob a responsabilidade de Marcelo Bonfler e os colaboradores da edição foram Chico Daniel e Rafael Guimarães.

Os integrantes, em sua maioria, eram formados em Jornalismo ou possuíam cursos superiores em áreas como História, Educação, Sociologia ou Ciência Política. Seus vínculos com o movimento pela reforma agrária foram firmados nas universidades em que estudaram, na participação em grupos políticos contrários à ditadura militar, na militância da CUT e do Partido dos Trabalhadores. As condições profissionais desses jornalistas eram variáveis, pois alguns dedicavam-se quase integralmente à produção do Sem Terra e eram subsidiados pelo CAMP, como Flademir Araújo e Humberto Monteiro. Outros, além de receberem pelo trabalho de free-lancer junto ao Centro de Educação Popular, exerciam profissões em jornais de Porto Alegre (RS) e de suas regiões, como também atividades na área de Educação. De maneira geral, estes produtores eram recém-formados que agregavam à militância apoio aos trabalhadores rurais sem-terra e o combate ao regime autoritário.

O apoio dado ao CAMP por agências de cooperação internacional foi intensificado através de parcerias com universidades, ONGs, governos e outras entidades. ${ }^{5}$ Assim, o Centro de Educação Popular apoiou projetos envolvendo movimentos sociais regionais e incentivou lideranças na discussão de temas relativos à organização popular.

A transição do Sem Terra de boletim a tabloide integrou um momento decisivo de unidade das lutas regionais perante a constituição de um movimento nacional. Organizado na cidade de Cascavel (PR), em janeiro de 1984, o I Encontro Nacional dos Trabalhadores Rurais Sem Terra oficializou o MST. O Encontro, além de simbolizar a unificação das lutas regionais, discutir temas relacionados à formação do movimento social, sua denominação, organização interna e perspectivas de ação, idealizou o Sem Terra como um órgão de "divulgação forte, amplo e que atingisse todo o país". (JORNAL SEM TERRA, 1984, n. 36).

Uma reunião específica em Curitiba (PR), no mês de junho de 1984, tratou da ampliação da tiragem - de 7.000 para 10.000 exemplares - com o objetivo de aumentar a circulação para diversas localidades do país. A necessidade de recursos para quantificar 
Um sem-terra ideal para um movimento nacional: representações políticas...

a tiragem e dar conta da demanda no crescimento da organização dos sem-terra era entendida, pela então definida Executiva Nacional, como fundamental na consecução do Projeto Jornal, elaborado com a finalidade de transformar o boletim em tabloide. Assim, o lançamento do Jornal dos Trabalhadores Rurais Sem Terra (JST) contou na composição com a responsabilidade dos integrantes do Jornal Mundo Jovem, na impressão com os serviços da Zero Hora Editora Jornalística e, na produção gráfica com o apoio do CAMP. O exemplar n. 36 fez um retrospecto de "uma história de três anos" do meio de comunicação e expôs as razões da mudança, enfocando as perspectivas de crescimento das tiragens. Além de evidenciar a importância dos lavradores no Projeto Jornal, enfatizou-se a conquista de novos leitores, a manutenção do tabloide e a contribuição do veículo de informação na organização dos sem-terra.

A regularidade na distribuição do jornal para variadas instituições que se identificaram com a causa contracenava com a deficiente presença do informativo nas bases da luta. A intervenção do editorial sobre a logística da divulgação direcionava a produção de materiais de informação para um centro urbano mais dinâmico, tanto em oportunidades de composição e impressão, como na viabilidade de circulação. Em 1985, a transferência para São Paulo do Jornal Sem Terra e da Secretaria Nacional do MST foi entendida pela Direção Nacional como um importante passo para o fortalecimento da luta e sua aproximação com o sindicalismo combativo da CUT. Assim, os Editores do Sem Terra, Flademir Araújo e Sérgio Carlos Canova, justificaram que:

"A transferência para São Paulo, centro político mais importante do país, indiscutivelmente, é explicada pelas facilidades que trará a organização dos sem-terra, tanto do ponto de vista político, como de estrutura e de divulgação do Movimento". (JORNAL SEM TERRA, 1985, n. 43).

Com a mudança para a capital paulista apostou-se numa nova etapa de melhoras e consolidação do Jornal Sem Terra. Instalada no Instituto Sedes Sapientiae, em São Paulo (SP), a equipe do jornal agregou novos jornalistas e colaboradores, traduzindo mudanças internas 
com o deslocamento da estrutura de produção. Esses jornalistas ampliaram a cobertura do Sem Terra para um maior número de Estados. Suas trajetórias tinham pontos em comum, sejam alguns formados em jornalismo, sejam outros que, ainda na universidade ou recentemente egressos, ajudavam na produção da notícia voluntariamente.

O jornal iniciou uma fase de atuação na organização e consolidação do MST em âmbito nacional. Nesse processo de ampliação do Sem Terra, a direção do movimento e dos produtores do jornal entraram num embate contra forças políticas da Nova República em decorrência de questões como o pacto social, o Plano Nacional de Reforma Agrária (PNRA) e a Assembleia Nacional Constituinte.

Mais do que noticiar a luta e divulgar cartas de leitores selecionadas, o que estava colocado em pauta era a consolidação de um movimento frente a questões de interesse nacional que envolvia, diretamente, a reforma agrária. O desafio que se estampava era a manutenção de uma organicidade interna, com debate intensificado a partir da fundação do MST. O Jornal Sem Terra, ao adquirir uma tendência de informação que primava por uma linguagem de fácil assimilação pelos trabalhadores rurais, abria uma lacuna no que se referia às notícias de temas mais complexos, como a formação de quadros, os embates políticos frente a temas nacionais e o internacionalismo que já se fazia presente na organização.

\section{O Jornal e as representações de trabalhador sem-terra}

A fundação do MST em 1984 deu representatividade às lideranças sem-terra através da formação da Direção Nacional, composta pela Coordenação Nacional e a Executiva Nacional. A Coordenação foi formada como um colegiado de líderes sem-terra, representantes dos Estados em que a organização estava presente, tendo a finalidade de, a partir das realidades regionais, debater e direcionar a luta num espectro nacional. Como um corpo diretivo de lideranças sem-terra, a Executiva foi definida como instância responsável pelas ações e representações do MST. 
Um sem-terra ideal para um movimento nacional: representações políticas...

A concepção de grupo e os valores impostos pela Executiva Nacional mediante seu jornal consistiram na interpretação da realidade da luta e na elaboração de significados para projetá-la. O tabloide divulgou as representações sociais que lideranças sem-terra e seus produtores fizeram de uma "realidade social como atuação", entendida por Cardoso (2000) como o cenário em que "[...] tomam forma as representações que tem por objeto ações sociais". Desse modo, o veículo de comunicação tornou-se estratégia para interpretar a luta e projetar o ideal pela reforma agrária.

Nesse campo de idealização da luta, o jornal conferiu competências aos trabalhadores rurais sem-terra. A atribuição partiu de um conjunto articulado de sentidos produzidos por sequências estabelecidas pela composição do jornal. O lugar ocupado por diferentes seções implica entender as diversas prioridades que a Executiva Nacional e a equipe de produção jornalística possuem sobre o que considera o leitor ideal (CHARTIER, 1996, p. 98), modelando ideias de atuação do trabalhador rural sem-terra na luta.

Fotografias, ilustrações, charges e cartoons uniram-se às manchetes, aos títulos, textos, às legendas, sobrepondo a diferença à semelhança e dando uma identidade ao jornal. (ZICMAN, 1981, p. 94-95). As mensagens jornalísticas propõem retratar os valores e a realidade dos trabalhadores rurais sob a perspectiva da Executiva Nacional. A partir do projeto gráfico, tendo como referencial a organização interna do JST, pode-se entender as representações da direção do movimento nesse período.

Ao constituir-se como porta-voz da Executiva Nacional do MST, o jornal exprimiu antes a condição de instrumento de divulgação de assuntos de interesse de um grupo atrelado à produção da notícia. Nesse sentido, instrumentar é oferecer material informativo para a operacionalização da luta, o que não significa conduzir o movimento. Entende-se o JST como um instrumento para a luta ao expressar projetos, perspectivas e notícias de interesse da Executiva Nacional que integram um ideal, que pode ser representado, instrumentalizado pela organização, mas não conduz ou determina o direcionamento do movimento, pois este se forja na prática.

Dar o parecer sobre acontecimentos, servindo de filtro entre a realidade e o que se desejava publicar sobre o MST, redundou no 
monopólio da Executiva sobre o jornal, possibilitando a atuação do tabloide na organização dos sem-terra mais como elemento que colaborou na aglutinação de ideias e, portanto, de uma pretensa identidade, do que espaço de confrontos e tensões existentes no movimento. A pretensa identidade, ao ser uma construção dos produtores da notícia do JST, sinalizou um "campo ideal” de competências para o leitor. (CHARTIER, 1996, p. 97).

A diversidade de assuntos apresentada pelo Sem Terra de 1985 a 1987 articulou-se à quatro temáticas que nortearam a composição do jornal nesse período: reforma agrária, violência, política e organização. Sendo eixos de discussão em diferentes momentos, caracterizaram-se por envolver outros temas como o pacto social, o Plano Nacional de Reforma Agrária (PNRA), a cooperação agrícola, a Constituinte, as ocupações e a formação de quadros do MST.

No processo de interpretação desses temas, três foram os tipos de trabalhadores rurais sem-terra idealizados pelo JST: "[...] o defensor da reforma agrária", "o atuante na cooperação agrícola" e "o contestador das vias institucionais". Essas idealizações foram competências que o jornal atribuiu aos trabalhadores rurais sem-terra a partir da prática do movimento em seu processo de definição nacional.

A competência de um trabalhador sem-terra defensor da reforma agrária, em 1985, marcou-se pela insistente reivindicação do jornal pela conquista da terra, colocando a reforma agrária como grande meta dos trabalhadores rurais naquele momento. Apesar do conhecimento de alguns simpatizantes e militantes a respeito das dificuldades a serem enfrentadas por futuros assentados, o enfoque foi a luta para repartir a terra.

Milhões de agricultores no Brasil querem um pedaço de chão para trabalhar e morar. Reforma Agrária não é apenas a repartição da terra, mas neste momento, é uma questão de sobrevivência. (JORNAL SEM TERRA, 1985, n. 46).

Apesar de encontrar perspectivas de atuação perante vias institucionais, como o Ministério da Reforma Agrária e do Desenvolvimento (MIRAD), o Instituto Nacional de Colonização e 
Um sem-terra ideal para um movimento nacional: representações políticas...

Reforma Agrária (INCRA), o pacto social proposto pelo Governo Federal, o Plano Nacional de Reforma Agrária (PNRA) e a Assembleia Constituinte; as principais atenções do tabloide voltaram-se para a ação direta dos sem-terra e sensibilização da sociedade civil quanto à importância da reforma agrária para o desenvolvimento da democracia no Brasil.

É perceptível, nas edições do n. 36 ao n. 48, publicadas entre 1984 e 1985, o crescimento da descrença da Direção Nacional do MST em relação aos projetos institucionais da Nova República. Em trecho publicado em 1984, o jornal enfatizou que:

Para os lavradores, mudar significa terra para trabalhar e o fim da violência. [...] O interesse é claro e legítimo: uma Reforma Agrária, sobre a qual muito se fala mas pouco se faz. Lutar por um pedaço de terra é caminhar concretamente para a conquista deste objetivo. (JORNAL SEM TERRA, 1984, n. 36).

O trabalhador sem-terra idealizado para defender a reforma agrária deveria atuar para entrar na terra. Isso foi retratado nas primeiras páginas dos exemplares de 1985. Num sentido geral era denotada uma visão simplista do MST com relação à reforma agrária. Esse momento foi entendido por Stédile (1997) como de planejamento para a consolidação da unidade do movimento, tendo na reforma agrária o eixo temático que sustentava as instituições envolvidas na luta pela terra. Pensava-se "[...] que Reforma Agrária era apenas a distribuição de terras e o fim dos latifúndios”. Entendia-se que tendo acesso a terra o camponês iria resolver os problemas de sua família. (STÉDILE, 1997, p. 105).

As manchetes do JST indagavam a respeito da realidade da população expropriada do campo e a necessidade de organização dos sem-terra. Defendiam a continuidade das ocupações de grandes extensões de terras improdutivas, marcando um momento da organização dos trabalhadores rurais através do emprego da palavra de ordem "Terra não se ganha, terra se conquista". (JORNAL SEM TERRA, 1985, n. 44). 
As fotografias se relacionavam diretamente com as principais manchetes. Para demonstrar a realidade do homem do campo que a mensagem escrita enfatizava, a fotografia expressava o sofrimento, as mortes, a dura caminhada para alcançar os direitos sociais e a situação do trabalhador acampado. Se a observação linguística concernia à necessidade de organização para se alcançar a reforma agrária ou à evidência das conquistas na prática, as fotografias enfocavam constantemente o coletivo através de aglomerações de trabalhadores em manifestações, acampamentos, assentamentos ou congressos.

As ilustrações feitas pelos cartunistas Fabiano, Vila e Bira, envolviam a organização dos trabalhadores rurais e as relações políticas do MST com os latifundiários e o Governo de José Sarney através do deboche. Os setores considerados contrários à reforma agrária eram expressos principalmente por fazendeiros através da obesidade e a sonolência perante os problemas sociais. Em contrapartida, os trabalhadores rurais eram desenhados com roupas simples, chapéus de palha e corpo esbelto, simbolizando a luta e a vivacidade em torno da conquista pela terra. O Governo Federal, expressado a partir do presidente José Sarney, gerava desconfiança nos trabalhadores pelas propostas como o pacto social e o PNRA, sendo referência para expressar as formas de repressão que se organizavam no projeto político da Nova República.

Mesmo visto com descrédito, o viés institucional alimentou esperanças do MST com relação à elaboração de um projeto de reforma agrária de interesse dos trabalhadores rurais. Com antecipação à finalização do PNRA, o Sem Terra abordou a estratégia política do Governo Federal:

A 'Nova República' fez um ponto ao propor, com ousadia, o seu Plano de Reforma Agrária. Com isto esvaziou, ou pelo menos adiou, a Reforma Agrária que interessa aos trabalhadores rurais. Do ponto de vista do governo, nada mais inteligente do que acenar com soluções aparentemente 'avançadas' para esfriar a tensão reinante no campo brasileiro e anunciar uma possível saída para a crise nacional. (JORNAL SEM TERRA, 1985, n. 46). 
Um sem-terra ideal para um movimento nacional: representações políticas...

O Governo Federal permitiu a participação dos trabalhadores rurais na apresentação de propostas para a elaboração do Plano Nacional de Reforma Agrária. As ideias dos sem-terra foram enviadas ao MIRAD e ao INCRA. Sobre esse assunto as referências do jornal estiveram presentes principalmente no Editorial. Suas matérias traduziam a preocupação da Executiva Nacional com a elaboração do PNRA. Por apresentar-se crítico, instigando mais a reflexão do que a opinião do jornal, o Editorial foi substituído pela seção Assunto para discussão. Essa seção ganhou espaço no tabloide a partir do final de 1985, com uma proposta que esboçou esperanças e criticou procedimentos do MIRAD e do Governo Federal perante a elaboração do PNRA.

Num sentido geral, esgotaram-se as perspectivas de negociação e acordo a favor da reforma agrária e ganharam as páginas do jornal, com mais intensidade a partir de 1986, temas como a violência no campo. A participação da Igreja Católica em questões conflituosas pela terra ganhou mais atenção no Sem Terra em momentos de acirramento da violência. A cobertura sobre a violência no campo articulava-se com a CPT, que lançara em 1985 e 1986 estudos sistematizados sobre "Conflitos de Terra no Brasil". ${ }^{\circ} \mathrm{O}$ envolvimento da CPT em estudos dessa ordem, levou a discussão da reforma agrária para o viés institucional por causa das perspectivas em torno das eleições de 1986 e a Constituinte. (JORNAL SEM TERRA, 1987, n. 60). O posicionamento do jornal sobre a violência colocava os trabalhadores rurais assassinados na condição de vítimas, difundindo um imaginário por meio da criação de mitos e mártires relembrados em datas reservadas para encontros, coberturas de eventos, apresentação de fotografias e matérias sobre os assassinados e os aniversários de suas mortes.

A configuração de forças políticas consideradas pelo MST como conservadoras a qualquer tipo de mudança que caracterizasse um amplo processo de desapropriação de terras tornou-se objeto de críticas do Sem-Terra. Em 1986, a ideia simplista de reforma agrária foi repensada, por causa dos problemas sociais e econômicos enfrentados por assentados. Era necessário, além da organização para o acesso à terra, a estrutura para manter-se nela. Assim, o jornal passou a abordar com frequência formas de produção baseadas na cooperação agrícola.

Anos 90, Porto Alegre, v. 20, n. 38, p. 327-352, dez. 2013 
A organização, portanto, foi enfocada de forma mais contundente. Possuía uma importância no momento histórico do movimento e do jornal, apresentando-se em quase todas as seções. Assim, assuntos relacionados aos temas entrelaçavam-se e passaram a fazer parte de um mesmo processo de discussão diante do estabelecimento do projeto político da Nova República e da proposta de organização do MST que se definia. A apresentação de resoluções de congressos, os resultados de ocupações, as formas de organização nos acampamentos, a formação política dos sem-terra, somavam-se às fotografias de militantes, lideranças e políticos enfocando um ambiente coletivo. A organização tornou-se objeto de análise em toda a composição do jornal, baseando-se numa linha clara, mediante a relação de representações do sujeito coletivo com o desenvolvimento do conhecimento da história, perspectivas e das ações organizativas.

A ideia de ocupação e mobilização do trabalhador sem-terra defensor da reforma agrária gerou uma discussão no jornal quanto à restrição da luta ao lema da conquista da terra. As manifestações e os debates enfatizaram a temática da cooperação agrícola no trabalho cotidiano dos assentados como forma de estruturação da luta. Esse tipo de trabalho foi entendido como um assunto importante a ser tratado pelo jornal dentro das temáticas elementares da política e organização.

Depois de muita luta, instalar-se num pedaço de chão não quer dizer que a 'guerra acabou'. Muitas vezes, a luta para ficar na terra e consolidar-se nela é mais dura e penosa do que a luta para conquistá-la. Conscientes dessa realidade e de que o êxito dos assentamentos é uma questão política, as lideranças dos assentamentos assumem o desafio, confiando na capacidade de organização dos trabalhadores. (JORNAL SEM TERRA, 1987, n. 60).

A competência de um trabalhador sem-terra atuante na cooperação agrícola decorria de implicações na manutenção da luta. Os assentamentos eram pontos importantes na organização do MST e gerava discussões na Executiva Nacional. Enfrentando problemas sociais e econômicos, muitos assentados não conseguiam se articular e 
Um sem-terra ideal para um movimento nacional: representações políticas...

perdiam a identidade da luta sem a presença ativa do movimento. Por isso, foram traçadas medidas de estruturação da cooperação agrícola, que primava pelo intercâmbio entre lideranças de assentamentos de vários Estados como elemento de consolidação das formas de organização dos assentados.

A cooperação agrícola era entendida como uma solução para os problemas de assentamentos. Lideranças sem-terra defendiam a articulação de uma equipe nacional para trocar experiências de diferentes projetos desenvolvidos no Brasil. (MEDEIROS, 1999, p. 29-30). Partia-se do pressuposto de incentivar a comercialização direta dos produtos dos acampados e assentados com associações urbanas, priorizando a produção coletiva.

Além disso, a estruturação dos assentamentos dependia da criação de equipes de formação que pudessem adequar cursos específicos à política de organização do MST, gestão administrativa e da própria cooperação. A formação política em todos os níveis e a intensificação do programa popular de educação primária e implementação da alfabetização dos adultos deveriam ser planejadas e executadas com materiais didáticos elaborados pelo próprio movimento. (CALDART, 1997, p. 31).

Não enfocar esse tipo de organização significava desmobilizar os trabalhadores rurais diante da falta de perspectiva que gerava a conquista da terra. Caso as possibilidades de manutenção nos assentamentos fossem difíceis, o enfraquecimento do movimento não seria evitado, na medida em que perderia forças pela própria inviabilidade do que se defendia. Dessa forma, a ideia de reforma agrária simplista cedeu espaço no Sem Terra para um projeto de conquista da terra sustentável, mediante a apresentação de mecanismos econômicos, políticos e sociais que o tema deveria envolver.

A resposta foi a organização como mecanismo de contestação, seja contra o projeto político conservador da Nova República, seja em oposição à violência da UDR. A contestação do jornal foi direcionada à aprovação do PNRA, à apresentação dos parlamentares que foram contra ou favoráveis às propostas dos trabalhadores rurais e à listagem de Deputados Constituintes ligados à UDR. 
Embora admitam que a Constituinte não vai resolver muita coisa, os trabalhadores sem-terra se organizam para se contrapor à força dos fazendeiros, mesmo contando com uma bancada inferior à UDR no Congresso Constituinte. (JORNAL SEM TERRA, 1987, n. 60).

A competência de um trabalhador sem-terra contestador partiu da descrença da Executiva Nacional ao viés institucional, posicionamento que se fez mais contundente por parte do jornal. Assumindo discussões de caráter nacional, a mudança de rumo do MST para a temática da organização pressupôs uma nova situação por parte dos dirigentes: a superação da simples visão local e estadual da luta, para enfrentar uma realidade nacional.

A aprovação do PNRA, os resultados das eleições de 1986 e a inflação após as tentativas de contenção do Plano Cruzado foram temas abordados com frequência pelo JST, traduzindo um distanciamento da via institucional como alternativa para se alcançar a reforma agrária. O que se defendia era a união entre os trabalhadores do campo e da cidade a partir da organização de uma política específica para a luta, integrados num partido autêntico a esse projeto, dentro de uma concepção de construção da CUT e do MST. (JORNAL SEM TERRA, 1987, n. 60).

Frases que anteriormente propunham a reflexão foram substituídas por afirmações como "A Constituinte está cada vez pior", "Reforma Agrária: Governo não faz, nós vamos fazer", "A enrolação da Constituinte", "Na força faremos nossas leis" e "Lutar para garantir grandes vitórias", geralmente atreladas a imagens de trabalhadores rurais sem-terra expressados em ambientes coletivos de mobilizações.

Entre as edições n. 63 e n. 69, o jornal preocupou-se com a apresentação de opiniões de intelectuais, simpatizantes e trabalhadores rurais sobre temas importantes no quadro político. A organização continuou sendo um dos assuntos mais abordados, relacionando-se com a formação política dos trabalhadores rurais sem-terra. Temas relevantes para o aperfeiçoamento da organização do MST foram tratados, tais como, a importância do estudo para a luta; o desafio de combinar a prática- teoria-prática; informações sobre a concentração de terras diante da História do Brasil; vantagens da cooperação 
Um sem-terra ideal para um movimento nacional: representações políticas...

agrícola do ponto de vista social, político, econômico e técnico; a construção da consciência e do projeto político dos trabalhadores rurais no processo histórico; procedimentos para se ensinar nos assentamentos; a importância do sindicalismo na organização do MST e assuntos para avaliação/planejamento do movimento.

Esses assuntos envolviam uma proposta de contestação do Sem Terra ao projeto político da Nova República.

Devemos melhorar cada vez mais nossa organização, porque somente a luta e a pressão farão leis adequadas às necessidades do povo. Somente a pressão fará com que o governo se convença que lhe falta legitimidade popular para governar esse país. (JORNAL SEM TERRA, 1987, n. 67).

Para a Executiva Nacional, a Assembleia Constituinte estava desmoralizada e os trabalhadores sem-terra deveriam contestá-la mediante a dedicação na organização do MST. Numa linguagem escrita de fácil assimilação, o jornal explanou a organização sob enfoques da prática e de teorias sociais que contavam com a participação de lideranças e professores na elaboração dos textos. Contestar significava organizar os sem-terra mediante a informação.

O invólucro dos temas do jornal nos anos de 1986 e 1987, com insistência na organização, foi a discussão política travada entre o MST e as vias políticas institucionais do país. Em forma de protesto, o jornal divulgou uma mensagem de contestação às instituições políticas:

Chega de enrolação dos Constituintes! Vamos rasgar e queimar a Constituição em praça pública! Fazer grandes e bonitas manifestações e comemorações, e conclamar toda a classe trabalhadora: já que na lei os nossos direitos não vêm, conquistaremos na marra! Quem não tem direito de fazer as leis, não tem obrigação de respeitá-las. Vamos colocar em prática as nossas leis. (JORNAL SEM TERRA, 1988, n.74). 
Com essa declaração, a Executiva Nacional do MST abandonou as esperanças de um amplo processo de desapropriação de terras, promessa inicial do projeto político da Nova República. A proposta de ocupação de terras se intensificou na pauta de organização:

Não podemos ter a ilusão que vamos ganhar terra com este governo ou com a nova Constituição. Antes da Nova República nós só conseguíamos terra, ocupando! Durante a Nova República, também só ocupando! E agora? Vamos esperar pelo governo? Pela Constituinte?. (JORNAL SEM TERRA, 1988, n.74).

A ocupação e resistência para serem intensificadas na prática requeriam um trabalho de organização. As perspectivas para o ano de 1988 priorizaram a formação política dos integrantes do MST. Dentro da meta de ligação das lutas do campo e cidade, vinculando-se as greves com as ocupações de terra, um dos grandes objetivos que se traçou no início desse ano foi a "massificação das lutas". (JORNAL SEM TERRA, 1988, n. 68). Pelo fato das ocupações e greves ocorrerem mais sob a influência de categorias ou organizações regionais, a "construção de um grande movimento de massa" foi condicionado pelas dificuldades de estabelecimento da unicidade. A representatividade dos trabalhadores rurais em muitos Estados não era permanente, o que prejudicava o desencadeamento das ocupações. (JORNAL SEM TERRA, 1988, n. 69).

Da edição n. 70 a n. 74, percebe-se que a Assembleia Constituinte deu fim às esperanças da Executiva Nacional de um projeto amplo de reforma agrária. Porém, longe de agradar as lideranças dos sem-terra, ofereceu condições estratégicas para a organização do MST. O jornal incentivou os trabalhadores rurais para continuar na luta. Argumentou que os sem-terra nunca viram atendidos seus pedidos sem sacrifício e mobilizações. O resgate da história da organização evidenciou no jornal a preocupação da Executiva Nacional quanto à valorização do passado na manutenção e construção da luta. Frases e desenhos com predominância da cor vermelha entrelaçavam-se a recados como "A força e o poder de um povo" ou "Eles queimaram nossos sonhos, 
Um sem-terra ideal para um movimento nacional: representações políticas...

nós queimaremos suas leis”, respectivamente referentes à organização ou do protesto. (JORNAL SEM TERRA, 1988, n.74).

A inserção de temas destinados à organização dos sem-terra através da significação coletiva caracterizada pelos símbolos, pela história, pelo planejamento e pela avaliação do grupo, definiu um projeto organizativo do MST diante do jogo de forças políticas na Nova República. O Jornal dos Trabalhadores Rurais Sem Terra consolidou-se como importante instrumento de difusão de ideias do MST. Em sua composição, evidenciaram-se posições da Direção Nacional do movimento perante a Nova República e as competências atribuídas aos trabalhadores rurais sem-terra, do defensor da reforma agrária ao contestador das instituições políticas, numa proposta coletiva de organização.

\section{AN IDEAL LANDLESS FOR A NATIONAL MOVEMENT: MST POLITICAL REPRESENTATIONS IN THE PAGES OF THE LANDLESS RURAL WORKERS' NEWSPAPER.}

Abstract: This article analyzes the representations of landless contained in the pages of the landless rural workers' newspaper in a period of formation of the New Republic and of national articulation of landless rural workers' movement (MST). The tabloid, organized by support entities and the MST management, became a diffusion instrument of proposals and prospects of mobilization, idealizing the landless rural worker as protagonist of the struggle for the land reform. Such representations were prepared by intellectuals, journalists, militants of the support entities and leaderships landless that, in the strains of elaboration and appropriation of the bulletin, delimited a space that, behind the apparent purposes of the struggles for land, found the struggle for communication.

Keywords: Newspaper. Representations. Landless rural workers movement.

\section{Notas}

${ }^{1} \mathrm{O}$ presente artigo resulta de pesquisas que constituíram a tese de doutorado em História, A luta divulgada: um movimento em (in)formação: estratégias, representações e politica de comunicação do MST (1981 - 2001), defendida em abril de 2007, na Universidade Estadual Paulista (UNESP/Assis-SP).

${ }^{2}$ Neste artigo, tomam-se como referência os meios de comunicação do MST produzidos numa periodização adotada na tese de doutorado, entre 1981 e 2001. 


\section{Fernando Perli}

Vale mencionar que, posteriormente a este período, outros materiais foram agregados à luta dos trabalhadores rurais sem-terra.

${ }^{3}$ A União Democrática Ruralista (UDR) foi organizada no Estado de Goiás e formalizada nacionalmente no ano de 1986. Na elaboração do Plano Nacional de Reforma Agrária e na Assembleia Constituinte apresentou-se como grupo contrário à proposta de reforma agrária defendida pelo MST. Vista pelo movimento como uma organização reacionária, a UDR ao se armar para defender a "propriedade privada" tornou-se um mecanismo de consequência direta no conflito entre fazendeiros e sem-terra. (CRUZ, 1987, p. 91-109).

${ }^{4} \mathrm{~A}$ formação de muitos jovens trabalhadores rurais que passaram a articular o "cutismo" resultou de reuniões promovidas pela CPT em comunidades rurais que auxiliavam o movimento de solidariedade pela luta dos sem-terra. Muitos destes jovens agricultores passaram a integrar uma oposição, originada do sindicalismo combativo,da política da FETAG junto à organização de trabalhadores rurais. Outros tiveram uma atuação mais intensa na própria CUT, compondo quadros de oposição à direção da central.

${ }^{5}$ O CAMP agregou forças ao seu trabalho através de agências financiadoras internacionais, como a Organização Intereclesiástica para a Cooperação ao Desenvolvimento (ICCO) da Holanda, a Katholische Zentralstelle für Entwicklungshilde (MISERIOR), da Alemanha; a Agência Britânica de Ajuda Humanitária (CHRISTIAN AID); a Fundação Católica para o Desenvolvimento (CAFOD), também da Inglaterra; a Development and Peace, do Canadá, e a Associação de Solidariedade Internacional (FRÈRES DES HOMMES), da França.

6 "Conflitos de terra no Brasil" tornou-se, no decorrer dos anos, uma referência nas publicações da CPT. O livro, lançado na anualmente desde 1985, retrata em números o panorama da violência no campo, servindo como instrumento de denúncia contra práticas ainda recorrentes no cenário rural brasileiro.

\section{Referências}

ANSART, Pierre. Ideologias, conflitos e poder. Rio de Janeiro: Zahar, 1978.

BLACKBURN, Robin, Depois da queda: o fracasso do comunismo e o futuro do socialismo. 3 ed. Rio de Janeiro: Paz e Terra, 2005.

BOURDIEU, Pierre. O poder simbólico. 3 ed. Rio de Janeiro: Bertrand Brasil, 2000. CALDART, Roseli Salete. Educação em movimento: formação de educadoras e educadores no MST. Petrópolis: Vozes, 1997.

Anos 90, Porto Alegre, v. 20, n. 38, p. 327-352, dez. 2013 
Um sem-terra ideal para um movimento nacional: representações políticas...

CARDOSO, Ciro Flamarion; MALERBA, Jurandir. (Orgs.). Representações: contribuição a um debate transdisciplinar. Campinas: Papirus, 2000.

CHARTIER, Roger. A bistória cultural; entre práticas e representações. Lisboa: Difel, 1990.

- (Org.). Práticas de leitura. São Paulo: estação Liberdade, 1996.

COMERFORD, John. Como uma família: sociabilidade, territórios de parentesco e sindicalismo rural. Rio de Janeiro: Relume Dumará/UFRJ, 2003.

CRUZ, Fernando Castro da. Reforma Agrária e sua evolução. São Paulo: Eud, 1987. IOKOI, Zilda Márcia Gricoli. As lutas camponesas no Rio Grande do Sul e a formação do MST. Revista Brasileira de História, São Paulo, v. 11, p. 49- 70, mar./ ago., 1991.

MEDEIROS, Leonilde Servolo de; LEITE, Sérgio. (Orgs.). A formação dos assentamentos rurais no Brasil: processos sociais e políticas públicas. Porto Alegre: UFRGS, 1999.

NAVARRO, Zander. (Org.). Politica, protesto e cidadania no campo: as lutas sociais dos colonos e dos trabalhadores rurais no Rio Grande do Sul. Porto Alegre: UFRGS, 1996.

SILVA, José Gomes da. Buraco negro: a reforma agrária na Constituinte. Petrópolis: Paz e Terra, 1989.

. Caindo por terra: crises da reforma agrária na Nova República. São Paulo: Busca Vida, 1988.

STÉDILE, João Pedro. A reforma agrária e a luta do MST. Petrópolis: Vozes, 1997. WENDHAUSEN, Henrique. Comunicação e mediação das ONGs: uma leitura a partir do canal comunitário de Porto Alegre. Porto Alegre: EDIPUCRS, 2003.

ZICMAN, Renê Barata. História através da imprensa: algumas considerações metodológicas. São Paulo: PUC, 1981.

Recebido em: 30 de julho de 2012. Aprovado em: 21 de março de 2013. 